\title{
Ethics in Sports Medicine
}

Editor

STEPHEN R. THOMPSON

\section{CLINICS IN \\ SPORTS MEDICINE}

www.sportsmed.theclinics.com

Consulting Editor

MARK D. MILLER

April 2016 • Volume 35 - Number 2 